\title{
СТАТЬИ
}

УДК 911(470.341)

РАЗВИТИЕ ГОРОДСКИХ ПОСЕЛЕНИЙ НИЖЕГОРОДСКОЙ ОБЛАСТИ

Аракчеева О.В., Кривдина И.Ю.

ФГБОУ ВО «Нижегородский государственный педагогический университет имени К. Минина», Нижний Новгород, e-mail: o.v.arakcheeva@rambler.ru

В статье рассматривается процесс динамики развития городских поселений в Нижегородской области с начала XX в., в которых сконцентрировано $80 \%$ всего населения региона. Выявлены факторы наиболее интенсивного оттока населения в города в различные исторические периоды развития Нижегородского региона, главным среди которых остается интенсивное развитие промышленности в области. В настоящее время в регионе насчитывается 28 городов, самым крупным из которых является город-миллионер Нижний Новгород, два больших города Арзамас и Дзержинск, пять средних городов - Саров, Бор, Кстово, Павлово, Выкса, восемь полусредних и 12 малых городов. Города Нижегородской области образуют определенную систему центров, взаимосвязанных с областным городом и между собой. Эти связи имеют промышленно-производственную, организационно-хозяйственную, трудовую и культурно-бытовую направленность. В зависимости от их географического положения и экономического развития разные города имеют разную дальность действия и разветвленность этих связей. За исследуемый период функции городов Нижегородской области претерпели некоторые изменения: большинство городов области остались монопрофильными организующими центрами; к административно-управленческим, промышленным и транспортным функциям добавились еще и финансовые, образовательные, туристические и рекреационные. В особую группу «неистинных» городов, «спущенных» администрацией сверху, можно выделить шесть городов в Нижегородской области: Ворсма, Горбатов, Ветлуга, Володарск, Перевоз и Княгинино, которые не выполняют свои функции и носят статус города формально. В настоящее время главные оси расселения проходят вдоль основных рек области - Волги и Оки, где сконцентрирован основной промышленный потенциал региона. Кроме Нижегородской агломерации, выделяются еще два района городского расселения - Павловско-Вачский и Выксунско-Кулебакский.

Ключевые слова: город, урбанизация, удельный вес городского населения, расселение, городские поселения

\section{DEVELOPMENT OF URBAN SETTLEMENTS OF NIZHNY NOVGOROD REGION}

\section{Arakcheeva O.V., Krivdina I.Yu.}

Nizhny Novgorod State Pedagogical University named after K. Minin, Nizhny Novgorod, e-mail: o.v.arakcheeva@rambler.ru

\begin{abstract}
The article deals with the dynamics of urban settlements development in the Nizhny Novgorod region since the beginning of the XX century, in which $80 \%$ of the total population of the region is concentrated. Factors of the most intensive outflow of the population to the cities in various historical periods of development of the Nizhny Novgorod region are revealed, the main among which remains intensive development of the industry in area. Currently, there are 28 cities in the region, the largest of which is the millionaire city of Nizhny Novgorod, two large cities Arzamas and Dzerzhinsk, five medium-sized cities - Sarov, Bor, Kstovo, Pavlovo eight semi-average and 12 small cities. The cities of the Nizhny Novgorod region form a certain system of centers, interconnected with the regional city and with each other by industrial and industrial, organizational and economic, labor and cultural relations. During the study period, the functions of cities of the Nizhny Novgorod region have changed: most of the cities in the region were single-industry centers; for administrative, industrial and transport functions has been added and the financial, educational, tourist and recreational. In a special group of «untrue» cities, there are six cities: Vorsma, Gorbatov, Vetluga, Volodarsk, Perevoz and Knyaginino, which do not perform their functions and have the status of a city formally. Currently, the main axes of settlement are along the Volga and Oka, where industrial potential is concentrated . In addition to the Nizhny Novgorod agglomeration, there are two more areas of urban settlement-PavlovskyVachsky and Vyksunsko-kulebaksky.
\end{abstract}

Keywords: city, urbanization, proportion of urban population, settlement, urban settlements

Стремительный рост городов и доли городских жителей является одним из наиболее динамичных процессов в системе расселения современной России. Урбанизация в научной литературе традиционно рассматривается как процесс усиления роли городов во всех сферах жизни общества. Нижегородская область представляет собой один из высоко урбанизированных регионов страны, отличающийся специфическими особенностями, обусловленными социально-экономическими процессами.
Цель исследования: выявление особенностей развития городских поселений Нижегородской области

\section{Материалы и методы исследования}

В Нижегородской области высокий уровень урбанизации. Удельный вес городского населения неуклонно возрастал в течение всего XX в. В настоящее время $80 \%$ жителей региона проживает в городской местности [1]. Наиболее активно процесс урбанизации протекал в 1930-е гг. (рис. 1). 
Нижегородское село стало «демографическим донором и активно поставляло рабочую силу в стремительно развивающиеся индустриальные центры и на эпохальные новостройки страны» [2].

Интенсивное развитие промышленности в области в послевоенные годы снова обусловило очень сильный отток сельских жителей в города [4]. В результате изменилась возрастно-половая структура населения, как городов, так и сельских населенных пунктов.

В соответствии с Реестром административно-территориальных образований [5] по состоянию на 1 января 2019 г. на территории Нижегородской области утверждены 52 административно-территориальные единицы - это 14 территорий, подчиненных городам областного значения (городских округов), и 38 муниципальных (администра- тивных) районов, на территории которых расположены еще 53 городских поселения.

За последние десятилетия произошли изменения и в количестве городских поселений в Нижегородском регионе, в целом их число уменьшилось с 94 в 1989 г. до 83 в настоящее время. Такая тенденция связана в первую очередь с изменением статуса поселков городского типа, большая часть которых, утратив статус ПГТ, перешла в разряд сельских поселений. Два населенных пункта вновь приобрели за исследуемый период статус города - Перевоз и Княгинино. Еще один город, появившийся за это время - Caров, который был выведен из разряда засекреченных в 1994 г., хотя статус города ему был присвоен еще в 1954 г. вместе с секретным названием Кремлев, когда в городе уже проживало около 47 тысяч человек (рис. 2).

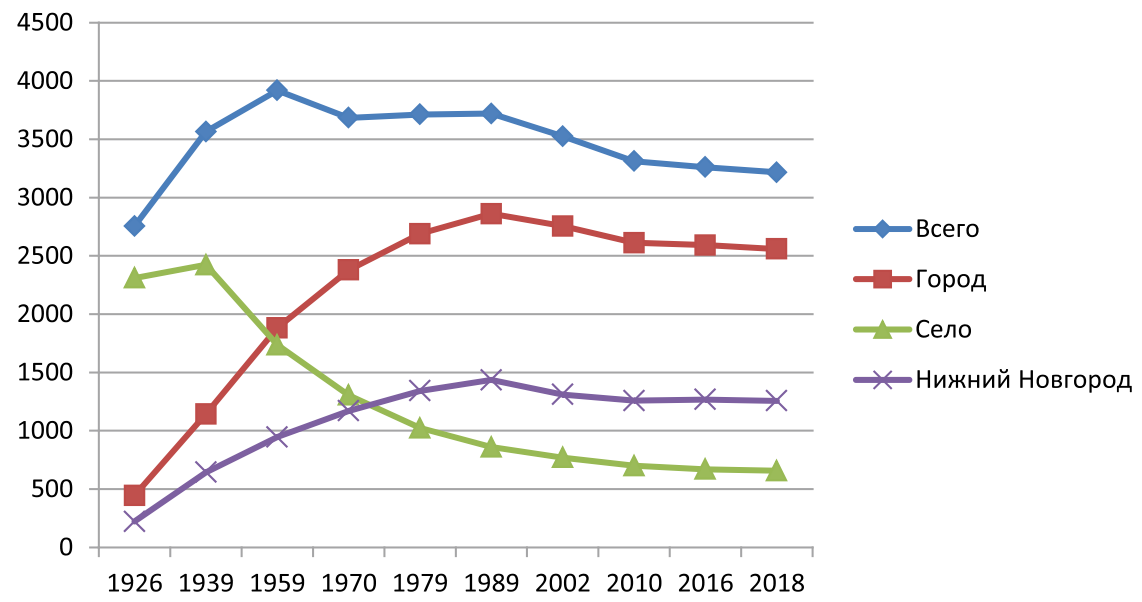

Рис. 1. Динамика численности населения (тыс. чел.) [3]

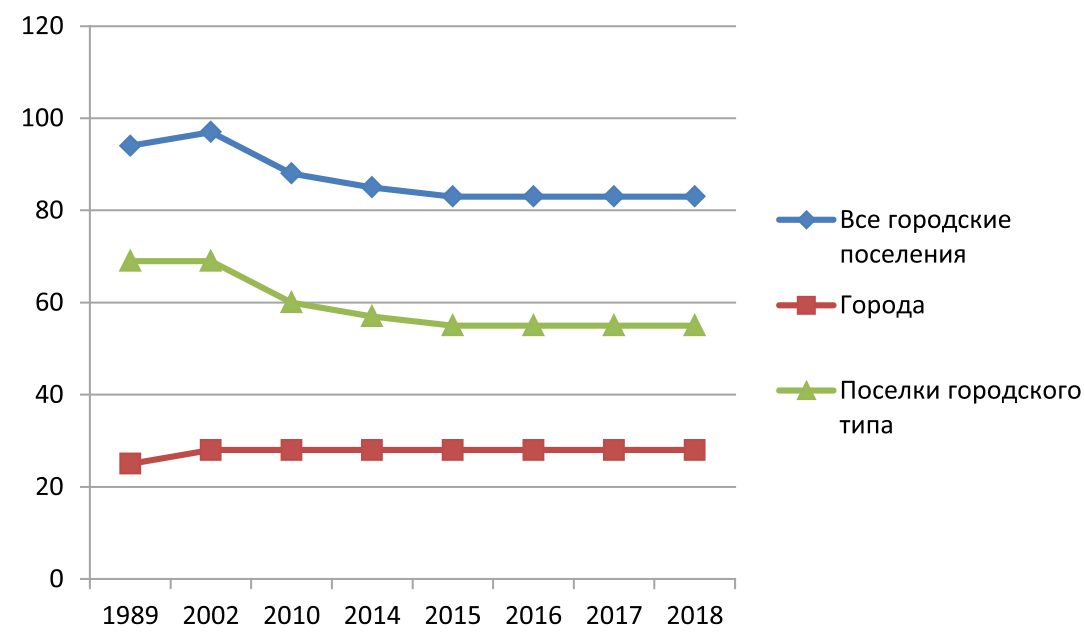

Рис. 2. Динамика числа городских поселений 
В целом в Нижегородской области насчитывается 28 городов, которые возникли в разные периоды исторического развития региона [6]. По времени образования можно выделить несколько групп:

- древние города, которые возникли до 1500 г. (Н. Новгород, Городец, Семенов);

- старые города, образовавшиеся в период с 1501 по 1900 г. (Арзамас, Балахна, Сергач, Лукоянов, Ветлуга, Перевоз, Княгинино, Горбатов);

- молодые города, образованные в период с 1901 по 1950 г. (Дзержинск, Павлово, Выкса, Бор, Кулебаки, Богородск, Лысково, Шахунья);

- новые города, получившие статус города позднее 1951 г. (Саров, Кстово, Заволжье, Навашино, Первомайск, Чкаловск, Урень, Ворсма, Володарск).

Самым крупным городом является Нижний Новгород, в котором насчитывается 1 млн 255 тыс. жителей, а самым малым - г. Горбатов, в котором проживает 1896 человек. Несмотря на внушительное количество городских поселений в Нижегородской области, роль и функциональная значимость областного центра - Нижнего Новгорода - остается весьма высокой. В Нижнем Новгороде сконцентрировано $39 \%$ населения всей области. Нижний Новгород входит в число 13 городов-миллионеров страны и занимает в списке пятую строчку после Москвы (12 615882 человек), СанктПетербурга (5 383890 человек), Новосибирска (1 618039 человек) и Екатеринбурга (1 483119 человек) [7]. Учитывая демографические процессы, происходящие в Нижнем Новгороде, можно предсказать, в ближайшие годы он переместится на шестую позицию, уступив место Казани, для которой характерен естественный прирост населения, в отличие от Нижнего Новгорода.

На территории Нижегородской области можно выделить следующие типы городов:

- миллионер (более 1 млн человек) Нижний Новгород;

- большие (100-250 тыс. человек) Дзержинск и Арзамас;

- средние (50-100 тыс. человек) - Caров, Бор, Кстово, Павлово, Выкса;

- полусредние (20-50 тыс. человек) Балахна, Заволжье, Богородск, Кулебаки, Городец, Семёнов, Лысково, Шахунья;

- малые (до 20 тыс. человек) - Сергач, Навашино, Лукоянов, Первомайск, Чкаловск, Урень, Ворсма, Володарск, Перевоз, Ветлуга, Княгинино, Горбатов.
Города Нижегородской области образуют определенную систему центров, взаимосвязанных с областным городом и между собой. Эти связи имеют промышленно-производственную, организационно-хозяйственную, трудовую и культурно-бытовую направленность. В зависимости от их географического положения и экономического развития разные города имеют разную дальность действия и разветвленность этих связей. Одни города выделяются организационной ролью (районные и межрайонные центры), другие - промышленным значением, а третьи - и тем, и другим вместе.

C переходом к рыночным отношениям выполняемые городами функции претерпелинезначительные изменения. Большинство городов области остались монопрофильными организующими центрами. Здесь лишь прибавились некоторые дополнительные функции, которые носят второстепенный характер. Например, к административноуправленческим, промышленным и транспортным функциям прибавляются еще и финансовые (районные центры являются местом сосредоточения представительств различных банковских структур), а также и образовательные (Дзержинск, Арзамас, Княгинино, Заволжье, Выкса, Кулебаки и др.). В производственной сфере расширяется специализация городов за счет более окупаемых и быстрооборотных отраслей (легкой, пищевой, мебельной и т.д.). Активно развиваются бизнес, туризм и рекреация (Городец и Семёнов).

Некоторые города Нижегородской области не выполняют свои функции и носят статус города формально. Это названные так В.П. Семеновым Тянь-Шанским «неистинные» города, «спущенные» администрацией сверху [8]. Таких городов в регионе шесть: Ворсма (10331 человек), Володарск (9907 человек), Ветлуга (8459 человек), Горбатов (1896 человек) и вновь вернувшие статус города - Перевоз (8740 человек) и Княгинино (6629 человек). По численности населения эти города не дотягивают до порогового значения 12 тыс. человек.

\section{Результаты исследования и их обсуждение}

К настоящему времени города области прошли огромный путь в своем развитии и увеличении людности. Однако есть и исключения: например, Володарск терял свое население из-за близости к более экономически притягательному городу Дзержинску, а в Горбатове уменьшение численности на- 
селения связано с утратой выгодного экономико-географического положения. В ряде городов (Балахна, Бор, Дзержинск, Нижний Новгород) увеличение численности населения шло за счет включения близлежащих населенных пунктов в черту города.

В программу развития монопрофильных городов России включены 12 городов Нижегородской области (Балахна, Володарск, Ворсма, Выкса, Заволжье, Кстово, Кулебаки, Павлово, Первомайск, Саров, Сергач, Шахунья). В этих городах предусмотрено развитие малого и среднего бизнеса, поддержание социальной сферы, привлечение инвесторов для создания новых предприятий, которые позволят расширить спектр выпускаемой продукции и организовать новые рабочие места для местных жителей. Также предусмотрена помощь градообразующим предприятиям, являющимся основными налогоплательщиками в местный бюджет.

Города области экономически связаны между собой и составляют территориальнопроизводственный комплекс. Это, прежде всего, касается городов с предприятиями, относящимися к главной в регионе отрасли промышленности - транспортному машиностроению и, в частности, автостроению (например, Нижний Новгород, Бор, Павлово, Арзамас, Лысково, Заволжье). Нижний Новгород как многоотраслевой индустриальный и административный центр оказывает большое влияние на развитие других городов области. Это влияние особенно ощутимо в радиусе 50 км на таких городах, как Бор, Дзержинск, Кстово, Балахна, Заволжье, Городец, Богородск и Володарск. Вместе с этими городами Нижний Новгород образует одно из крупнейших в стране скоплений (агломераций) городских поселений. Внутри Нижегородской городской агломерации осуществляются тесные производственные связи, обеспечивающие нормальное развитие хозяйства; культурно-бытовые связи, направленные на удовлетворение материальных и духовных запросов населения; рекреационные (выезд на отдых); трудовые (ежедневные поездки на работу из одного населенного пункта в другой).

Исследуя численность населения городов Нижегородской области в период с первой переписи (1897 г.) [9] или от даты возникновения города до 2019 г., можно выделить несколько групп городов:

- города, увеличившие численность населения более чем в 10 раз - Арзамас, Бор, Кстово, Саров, Дзержинск, Н. Новгород, Перевоз, Чкаловск, Первомайск;
- города, увеличившие численность населения от 2 до 10 раз - Выкса, Лукоянов, Семёнов, Павлово, Городец, Сергач, Княгинино, Ворсма, Лысково, Богородск, Балахна, Шахунья;

- города, увеличившие численность населения до 2 раз - Заволжье, Ветлуга, Кулебаки, Навашино, Урень;

- стагнирующие города - Горбатов;

- города, теряющие население-Володарск.

Городские поселения Нижегородской области включают не только города, но и 53 поселка городского типа. Эти населенные пункты представляют собой несформировавшиеся в полной мере города, либо утратившие статус города населенные пункты [10]. В Нижегородской области таковыми являются Варнавино, Ардатов, Макарьев, Васильсурск и др. Среди них по численности населения выделяются Ардатов и Шатки - в них насчитывается более 8 тыс. чел., в то время как в пгт. Шайгино Тонкинского района и пгт. Лесногорск Шатковского района - немногим более 800 чел.

Bce поселки Нижегородской области можно разделить на следующие группы:

- крупные пгт. - составляет от 5 до 10 тыс. чел. (Ардатов, Мухтолово, Выездное, Большое Козино, Гидроторф, Большое Мурашкино, Бутурлино, Вача, Вознесенское, Ильиногорск, Решетиха, Воротынец, Воскресенское, Досчатое, Ковернино и др.);

- небольшие пгт. - типа от 3 до 5 тыс. чел. (Горбатовка, Виля, Лукино, Варнавино, Шиморское, Дальнее Константиново и др.);

- мелкие пгт. - менее 3 тысяч жителей (Гавриловка, Малое Козино, Фролищи, Желнино, Первое мая, им. М.И. Калинина, Красная Горка, Смолино, Центральный, Юганец, Васильсурск, Ближне-Песочное, Первомайск и др.).

Большинство поселков городского типа в регионе относятся к крупным и мелким населенным пунктам 49\% и $38 \%$ соответственно, к небольшим всего лишь 13\% (рис. 3).

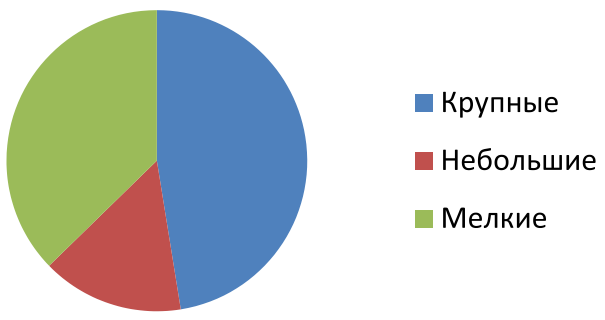

Рис. 3. Доля поселков городского типа Нижегородской области по численности населения 


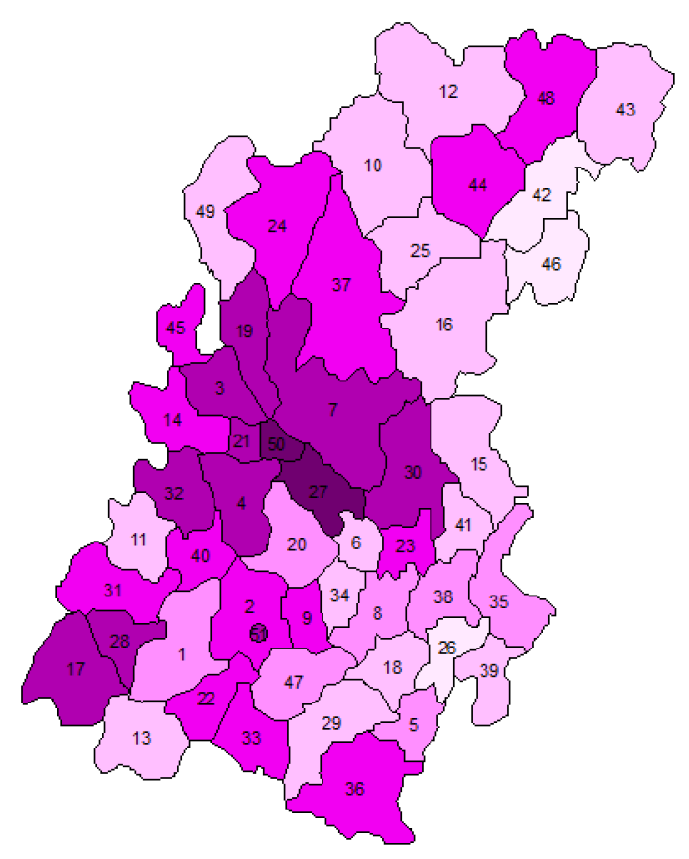

менее 100,0

100,1 - 500,0

$500,1-1000,0$

$1000,1-5000,0$

$5000,1-300000,0$

более 300000,1
Муниципальные районы

и городские округа

1 Ардатовский

2 Арзамасский

3 Балахнинский

4 Богородский

5 Большеболдинский

6 Большемурашкинский

7 г. Бор

8 Бутурлинский

9 Вадский

10 Варнавинский

11 Вачский

12 Ветлужский

13 Вознесенский

14 Володарский

15 Воротынский

16 Воскресенский

17 г. Выкса

18 Гагинский

19 Городецкий

20 Дальнеконстантиновский

21 г. Дзержинск

22 Дивеевский

23 Княгининский

24 Ковернинский

25 Краснобаковский

26 Краснооктябрьский
27 Кстовский 28 г. Кулебаки 29 Лукояновский 30 Лысковский 31 Навашинский 32 Павловский 33 г. Первомайск 34 Перевозский 35 Пильнинский 36 Починковский 37 Семеновский 38 Сергачский 39 Сеченовский 40 Сосновский 41 Спасский 42 Тонкинский 43 Тоншаевский 44 Уренский 46 Шарангский 47 Шатковский 48 г. Шахунья 49 Сокольский 50 г. Н. Новгород 51 г. Арзамас

Рис. 4. Производство товаров, работ и услуг в Нижегородской области в 2018 г. (млн руб.)

Людность поселков определяется в значительной степени их промышленно-производственным потенциалом: чем он выше, тем больше занятость в производственной сфере и тем крупнее поселок [11]. Влияет на численность населения и выполнение поселками центральных, управленческих и обслуживающих функций. Если такие функции выполняются, то достаточно большой оказывается занятость в непроизводственной сфере, что, соответственно, ведет к росту населения. В ряде случаев характерна большая людность для поселков, не имеющих промышленности и не выполняющих центральных функций. Это поселки, лежащие вблизи крупных промышленных центров, где и работает их трудоспособное население.

\section{Заключение}

В настоящее время главные оси расселения проходят вдоль основных рек области - Волги и Оки, где сконцентрирован основной промышленный потенциал региона (рис. 4). Кроме Нижегородской агломерации, выделяются еще два района городского расселения - Павловско-Вачский и Выксунско-Кулебакский.

Эти населенные пункты имеют хорошую транспортную связь с областным центром или другими центрами городской агломерации, высоким уровнем благоустройства (детские сады, школа, медицинские учреждения, дом культуры, почта, сберкасса, магазины и т.п.). Соответственно, здесь можно удовлетворить многие потребности населения и есть возможность трудоустройства не только в аграрной сфеpe, но и в непроизводственной сфере самого населенного пункта, а также на предприятиях ближайшего города.

ПГТ выполняют в основном роль административных районных центров, либо вспомогательных промышленных и транспортных центров при городах. Однако последние в начале XXI в. испытывают кризис 
в результате упадка промышленного производства (поселок им. Парижской Коммуны, поселок Калинина и др.). Некоторая стабилизация наблюдается лишь в райцентрах, так как здесь аккумулируются и перераспределяются все экономические, финансовые, в большинстве случаев транспортные функции района и сосредоточен весь административно-управленческий аппарат.

\section{Список литературы / References}

1. Аракчеева О.В., Кривдина И.Ю. Миграции населения Нижегородской области // Успехи современного естествознания. 2018. № 12-2. С. 339-344.

Arakcheeva O.V., Krivdina I.Yu. Migration of the population of the Nizhny Novgorod region // Advances in current natural sciences. 2018. № 12-2. Р. 339-344 (in Russian).

2. Вознесенская А.Г. Трансформация геодемографических процессов в сельской местности Нижегородской области. // В сборнике Трансформация географических процессов на территории регионов России и мира. Современные проблемы географического образования в вузе и школе. Н. Новгород: НГПУ, 2009. С. 54-60.

Voznesenskaya A.G. Transformation of geodemographic processes in rural areas of Nizhny Novgorod region. / V sbornike Transformatsiya geograficheskikh protsessov na territori regionov Rossii i mira. Sovremennyye problemy geograficheskogo obrazovaniya v vuze i shkole. N. Novgorod: NGPU, 2009. P. 54-60 (in Russian).

3. Вознесенская А.Г., Аракчеева О.В. Население Нижегородской области: динамика численности, естественное и механическое движения // Вестник Мининского университета: сетевое издание. 2013. № 4 [Электронный ресурс]. URL: https://vestnik.mininuniver.ru/jour/article/view/442 (дата обращения: 25.11.2019)

Voznesenskaya A.G., Arakcheeva O.V. Population of the Nizhny Novgorod region: population dynamics, natura and mechanical movements.Vestnik Mininskogo universiteta network edition. 2013. № 4 [Electronic resource]. URL: https:// vestnik.mininuniver.ru/jour/article/view/442 (date of access: 25.11.2019) (in Russian).

4. Аракчеева О.В., Кривдина И.Ю. Этапы миграционных движений населения на территории Нижегородской области // Успехи современного естествознания. 2017. № 6. C. $72-76$.

Arakcheeva O.V., Krivdina I.Yu. Stages of migration movements of the population on the territory of the Nizhny Novgorod region // Advances in current natural sciences. 2017. № 6. P. 72-76 (in Russian).

5. Краткий статистический сборник Нижегородская область в цифрах 2019. [Электронный ресурс]. URL: http:/ nizhstat.old.gks.ru/wps/wcm/connect/rosstat_ts/nizhstat/ru/ publications/official_publications/electronic_versions/ (дата обращения: 25.11.2019)

Brief statistical collection Nizhny Novgorod region in numbers 2019. [Electronic resource]. URL: http://nizhstat. old.gks.ru/wps/wcm/connect/rosstat ts/nizhstat/ru/publications/official publications/electronic versions/ (date of access: 25.11.2019) (in Russian).

6. Вознесенская А.Г., Валяев И.А, Лебедев А.В. Эволюция системы расселения северо-западных районов Нижегородской области // В сборнике Инновационные процессы в современной географии: научные и образовательные аспекты. Н. Новгород: ООО Типография «Поволжье», 2012. C. $137-142$.

Voznesenskaya A.G., Valyaev I.A., Lebedev A.V. Evolution of the settlement system of the North-Western districts of the Nizhny Novgorod region // V sbornike Innovatsionnyye protsessy $\mathrm{V}$ sovremennoy geografii: nauchnyye $\mathrm{i}$ obrazovatel'nyye aspekty. N. Novgorod: OOO Tipografiya «Povolzh'ye», 2012. P. 137-142 (in Russian).

7. Города-миллионеры России 2019. [Электронный pecypc]. URL: https://www.sites.google.com/site/ruregdatav1/ goroda-millionniki-rossii-po-naseleniu (дата обращения: 25.11.2019).

The Millionaire Cities of Russia 2019. [Electronic resource]. URL: https://www.sites.google.com/site/ruregdatav1/ goroda-millionniki-rossii-po-naseleniu (date of access: 25.11.2019) (in Russian).

8. Серко Е.Ю. Города Нижегородской области // Нижегородская область четверть века социальных перемен (к 300-летию создания Нижегородской губернии). Н. Новгород: НГПУ им. К. Минина, 2013. С. 146-152.

Serko E.Yu. Cities of Nizhny Novgorod region// Nizhegorodskaya oblast' chetvert' veka sotsial'nykh peremen $(\mathrm{k}$ 300-letiyu sozdaniya Nizhegorodskoy gubernii). N. Novgorod: NGPU im. K. Minina, 2013. P. 146-152 (in Russian).

9. Первая Всеобщая перепись населения Российской империи 1897 г.: [кн. 1-89] / под ред. Н. А. Тройницкого. Санкт-Петербург: издание Центрального статистического комитета Министерства внутренних дел, 1899-1905. [Электронный ресурc]. URL: https://www.prlib.ru/item/436650 (дата обращения: 25.11.2019).

The first General census of the population of the Russian Empire in 1897: [kn. 1-89]/ pod red. N. A. Troynitskogo. Sankt-Peterburg: izdaniye Tsentral'nogo statisticheskogo komiteta Ministerstva vnutrennikh del, 1899-1905. [Electronic resource]. URL: https://www.prlib.ru/item/436650 (date of access: 25.11.2019) (in Russian).

10. Кряжев А.Б. Поселки городского типа. // Отечество мое Нижегородское: книга для чтения / Сост. Г.С. Камерилова. Н. Новгород: Нижегородский гуманитарный центр, 1997. C. 294-299.

Kryazhev A.B. Urban-type Settlements.// Otechestvo moye Nizhegorodskoye: kniga dlya chteniya / Sost. G.S. Kamerilova. N. Novgorod: Nizhegorodskiy gumanitarnyy tsentr, 1997. P. 294-299 (in Russian).

11. Орфанов И.К. Проблемы реконструкции сельского расселения Нечерноземья РСФСР // Географические аспекты реконструкции населенных мест Нечерноземья: сборник статей. М.: ГО СССР, 1984. С. 3-10.

Orfanov I.K. Problems of reconstruction of rural settlement of the non-black earth region of the RSFSR // Geograficheskiye aspekty rekonstruktsii naselennykh mest Nechernozem'ya: sbornik statey. M.: GO SSSR, 1984. P. 3-10 (in Russian). 